\title{
CHARACTERISTICS OF PEDAGOGICAL CONDITIONS FOR PREPARING FUTURE PRIMARY SCHOOL TEACHERS TO INTERACTION WITH PARENTS IN TERMS OF INCLUSIVE EDUCATION
}

\author{
Maryna Bevzyuk \\ Preschool and Special Education Department \\ Pavlo Tychyna Uman State Pedagogical University \\ 2 Sadova str., Uman, Ukraine, 20300
}

\begin{abstract}
In the article, based on the scientific sources and empirical material analysis, the pedagogical conditions of future primary school teachers' preparation for interaction with parents in terms of inclusive education have been described. They are: stimulation of future primary school teachers' motivational-value and responsible attitude to the knowledge acquisition, skills and habits of interaction with parents in terms of inclusive education; the use of training facilities for higher educational institutions to acquire future primary school teachers' appropriate competence through: improvement and integration of the professional and professionally oriented academic disciplines content, application of innovative and traditional learning technologies in the context of preparation for interaction with parents in the context of inclusive education; direction of educational and pedagogical practice on experience improvement of future primary school teachers' interaction with parents in terms of inclusive education. It has been specified that only the harmonized observance of all conditions will be a guarantee of qualitative future primary school teachers' preparation to interacting with parents under inclusive education conditions. With the purpose of special teachers training to form future primary school teachers' ability to interact with parents in terms of inclusive education it has been recommended to conduct not only traditional educational and methodological or scientific-practical seminars, but also trainings, coaching, webinars, first of all, in online mode. It has been indicated that such forms of work nowadays become very popular because of their availability, dedication to production and innovation: extra-mural/distance participation; easy access to social networks and websites; the practical nature of the information: empirical material with confirmatory video stories; providing specific advice on decision making in pedagogical situations; the possibility of revising in case of indirect participation and in the situation of certain aspects additional clarification; constant information updating taking into account the most recent trends and so on.
\end{abstract}

Keywords: pedagogical conditions, professional training, future primary school teachers, interaction with parents, terms of inclusive education.

\section{Introduction}

New social dimensions of the Ukrainian state challenge the educators with regard to the pedagogical field modernization. Such requirements primarily concern the organization of schoolchildren's inclusive education. This issue is agreed at the regulatory level in the new version of the Law of Ukraine "On Education", which actualizes scientific researches of the above-mentioned line, especially in the field of future teachers' training for the inclusive education organization. Priority, from the scientific point of view, is the emphasis on the choice of a special age group of participants in the educational process and their interaction. This is primarily about primary school pupils, their parents and primary school teachers.

Contemporary studies on inclusive education are aimed at introducing its basic principles, primarily in developing countries. A. Masud, M. Jahirul state that in some countries discrimination against children with special needs continues, coupled with a high dropout rate for students from socio-economically disadvantaged groups. Such countries implement the policy of reforming educational systems. For example, in Bangladesh, a number of acts have been introduced to support the reform of inclusive education in ordinary schools [1]. The research has been conducted in the context of primary education in Bangladesh to study the conditions affecting teachers' attitudes toward inclusion of students with special needs into ordinary classes. The results have shown that inclusive education is better realized by taking into account demographic factors and continuing education experience of students with special needs. However, the main condition is teachers' posi- 
tive attitude towards inclusive education [2]. The study of the inclusion of special needs students in regular Botswana schools has shown that teachers prefer to teach students with weak special needs in ordinary classes. Instead, pupils with complicated forms of special needs are more appropriate to be taught at home or in special institutions. Among the obstacles to the introduction of inclusive education the lack of resources, preparation level of students (young specialists), and the diversity of the Botswana culture, which includes regional ethnic differences, have been named [3]. In Zimbabwe, the results have demonstrated the need for more coordinated cooperation between the structural units of education (with the provision of health care), as obstacles in such a country are also distance and transport. Other innovative solutions can come from communities themselves, but they also require resources and support [4]. Considering the individual character of inclusive education organization in each country, there is a lack of research on the implementation of inclusive education in post-Soviet countries, in particular, Ukraine. At the same time, researchers emphasize the main condition for organizing inclusive education at primary school for the future teachers training, but do not detail this issue. In general, in the studies, there is an aspect such as the peculiarities of the interaction of primary school teachers with the pupils' parents in the context of inclusive education.

\section{Aim of research}

The aim of the article is to characterize on the basis of scientific sources and empirical material analysis pedagogical conditions of preparing future primary school teachers to interaction with parents in terms of inclusive education.

\section{Materials and Methods}

We have chosen theoretical methods of research: analysis, synthesis of comparison, etc. The application of these methods will allow us to characterize the pedagogical conditions of future primary school teachers training to interact with pupils' parents in the context of inclusive education - the factors that contribute to the effectiveness of this process.

Emphasizing the pedagogical conditions of the investigated process, we will focus on two conceptual components: "teachers' professional interaction with pupils' parents" and "inclusive education". It is logical to assume that general pedagogical conditions for the future primary school teachers training to interact with parents in the context of inclusive education should be distinguished on the basis of analysis and agreement of the already studied pedagogical conditions of the conceptual components.

Thus, scholars [6] distinguish the following components in studying the context of problems of teachers' professional interaction with pupils' parents. They are:

- a steady need for communication in this direction; positive humanistic orientation of pedagogical activity;

- the system of scientific and theoretical knowledge, in particular - special (the theory of communication, fundamentals of family pedagogy);

- mastering the practical work experience (the optimal communication technique);

- the ability to reflect the process of such communication (to evaluate the result through the prism of achieving the goal).

Based on the generally accepted notion of "readiness for activity", we can state that the above mentioned process of teachers' professional interaction with pupils' parents has four components: motivational, cognitive, operational and socio-psychological (reflexive).

According to the results scientific research, the professional training of future primary school teachers to interact with parents implies their readiness for the following functions implementation: developmental; educational mobilization; prognostic; organizing; communicative; preventive; controlling; protective; corrective (social-therapeutic) [5]. Such functions include, in our opinion, operational and socio-psychological (reflective) components of future primary school teachers' readiness to interact with pupils' parents.

It is obvious that the isolation of the pedagogical conditions for preparing future primary school teachers to interaction with parents involves taking into account these features. 
Scientifically significant is the research by L. Hutsulyak on the interaction of teachers, parents and community in the socio-educational primary school environment in the United States of America. The author describes the main types of teacher assistance from pupils' parents:

- joint implementation of family homework tasks, first and foremost, educational projects and creative tasks made by educators;

- organization and management of children's cognitive activities at home, that is, the creation of a special social and educational environment in the family;

- parents' participation in the school's activities (volunteering, advisory forms, various parent organizations activities); reading);

- the formation of family habits and traditions (gifts during school holidays, joint books

-parents' activity as certain subjects tutors, etc. [7, p. 10].

On the basis of the mentioned pedagogical concept "teachers, parents and community interaction in the primary school social and educational environment" defines it as "the system of social relations aimed at the comprehensive child development of the junior school age, its positive socialization, social and legal support in different forms of activity, positive motivation development for a healthy lifestyle, resistance to negative manifestations of society" [7, p. 10].

The above mentioned study allows us to take into account foreign pedagogy experience regarding the preparation of future primary school teachers to interact with pupils' parents, especially during the implementation of the Concept "New Ukrainian School", the leading ideas of which are the partnership terms of cooperation between teachers and pupils' parents.

The pedagogical conditions for improving future teachers' vocational training for professional activities in the context of cooperation with parents have been determined by scholars $[5,6]$ as:

- providing a positive motivation to this type of activity;

- modernization of the vocational training content (for example, harmonization of educational disciplines contents of different cycles, educational disciplines integration, etc.);

- educational and methodological support improvement of the mentioned process;

- special university teachers' training;

- priority of pedagogical practice, students' independent work;

- intensification of educational process in institutions of higher education (selection of optimal training technologies, forms, methods and means);

- development and application of future teachers' socially oriented training technology, etc.

At the same time, these conditions are generalized only by us. In scientific research they are presented in a scattered manner and do not form a system of future primary school teachers' professional training to interact with parents in the context of inclusive education. First of all, the research does not focus on the motivational component of such training and the practical component of the professional training process of the indicated direction is described separately.

From the practical point of view, the scientific values in the context of our study have been described [6]. They relate to the characteristics of educational disciplines integration in the process of future primary school teachers' professional training to interact with parents. Based on the results analysis, the following statements are chosen for the experimental part of our study:

1. The implementation of academic disciplines integration must be carried out in the following stages: content analysis of educational disciplines; determination of the possibilities of studying the indicated problems in studying disciplines cycles; special teachers' training (first of all, the teaching activities coordination by analyzing and coordinating the disciplines content); organization of educational disciplines integration in the educational process of higher educational institutions.

2. At the first stage (content analysis of the disciplines included to the knowledge field 01 "Education", specialty 013 Primary Education) it is necessary to take into account that the problem of future primary school teachers' professional training to interact with parents in terms of inclusive education should take into account two information contents, that is, "teacher's interaction with pupils" parents" and "terms of inclusive education". Separately indicated information planes are studied in detail and fragmentary in the context of many disciplines studying. However, we have discovered the attendant students' problems studying these concepts: 
- even approaches to understanding the concept of "teacher's interaction with pupils' parents" in the content of studying different disciplines is non-one-dimensional;

- the notion of "inclusive education conditions" is predominantly of a theoretical nature (for example, the legal aspect: the legislative basis and normative ways of its realization);

- there is a lack of coherence in the content study of these problems; for example, the contradictory result of future teachers' meaningful comprehension of the concept of "teacher's interaction with pupils' parents": "It seems like different phenomena, which are simply designated by one term, are analyzed. In parallel with pedagogy and psychology, students listen to courses in sociology, philosophy, which also refers to the family, but its characteristics are different and, at least, at first glance, have little in common with the first one. The relationship of philosophical understanding of the family (moreover, in the educational literature is not sufficiently clear) with the psychological and pedagogical are also not analyzed. As a result, students may naturally think that pedagogy and psychology in this matter are on their own, and philosophy, as the world-wide and methodological science is on its own" [6, p. 70].

3. The major semantic and informational opportunities in the aspect of the future primary school teachers' professional training to interact with pupils' parents in terms of inclusive education are the following disciplines: "Introduction to Pedagogical Activity", "Fundamentals of Pedagogy and Psychology", "Theory of Education", "Pedagogical Technologies in Primary School", "Fundamentals of Pedagogical Excellence", "Pedagogical Psychology", "Fundamentals of Psychodiagnostics".

"...the assimilation of a set of certain knowledge is impossible in the framework of one educational subject. In order to capture and consolidate them at the skills level, these skills and abilities must be permanently used in the next training activity" [6, p. 70].It is necessary that each teacher imagined the student training system, knew that it had already worked out in other classes. For the purposes of such work the author recommends conducting training seminars for teachers in order to coordinate educational activities in preparing students for pedagogical interaction with pupils' parents.

A separate scientific interest in the context of our study is caused by scientific research, tangential inclusive education. The Law of Ukraine "On Education" provides two key interpretations of this notion:

"12) inclusive education is a system of educational services guaranteed by the state, based on the principles of non-discrimination, taking into account human diversity, effective involvement and inclusion all its participants in the educational process;

13) inclusive educational environment is a set of conditions, methods and means of their realization for the joint education and development of education applicants, taking into account their needs and possibilities..."[9].

In addition, in the same Law, Article 20 is singled out as "Inclusive Education" [9]. Thus, for the first time, the Law clarifies the essence of the concept under study and specifies the normative and legal framework for the organization of inclusive education.

Scientists interpret the notion "primary school teacher's professional activity in terms of inclusive education" as "a motivated set of basic and additional teacher's functions, the qualitative execution of which in close cooperation with social and correctional teachers, psychologists, medical workers and parents ensures success of solving the problems of psychological, pedagogical, educational and correction-development work for effective education, upbringing and development correction of junior pupils with special educational needs and without them" [8]. However, in this interpretation, the component "interaction with parents" is mentioned only in the definition system.

Defines pedagogical conditions of future primary school teacher's readiness formation for professional activity in inclusive education as:

- directing the content of the programs and educational methods of teaching subjects to students' acquisition of inclusive education axiology;

- improvement of the content, forms, methods, means of mastering the normative, psychological, pedagogical, corrective, and scientific bases of inclusive education by students in the studying individual disciplines process; didactic and correction-developmental technologies in classes on professional methods of primary school subjects teaching; 
- deepening of professional knowledge, students' practical skills in the process of studying individual disciplines on the basis of simulation modeling and reflection of primary school teacher's pedagogical activity experience in terms of inclusive education with the corresponding contents updating of pedagogical practice program [8].

As we can see, the researcher has emphasized on improving the content and methodology of teaching individual disciplines in the process of future primary school teachers' professional training to work in terms of inclusive education. Among the educational disciplines the author has chosen: "Philosophy", "History of Pedagogy", "History of Ukrainian Culture", "Didactics", "Theory and Methods of Education", "Pedagogical Psychology", "Political Science", "Pedagogical Exellence", "Fundamentals of Medical Knowledge", "Fundamentals of Defectology", "Fundamentals of Corrective Pedagogy", "Fundamentals of Inclusive Education", "Psychology of Creativity", "Inclusive Primary School Pedagogy".

However, the definition of junior pupils' parents as educators in accordance with the Law of Ukraine "On Education" [9] by the participants in the educational process, the component "interaction with parents" in the context of future primary school teachers training should be a priority.

Studies determine number of factors, needed for effective inclusive education:

- proper training of teachers who could consistently respond to all pupils' needs;

- the assertion of teacher's right to choose the implementation of inclusive classes;

- encouraging teachers to develop proposals for inclusive education;

- cooperation between the main teachers and teachers of the inclusive classes;

- orientation only on pupils' needs, and not external ideology;

- individual training program to meet all pupils needs;

- assessment and monitoring of children's educational dynamics and additional services;

- parents' involvement and participation in the educational process, first of all for making important decisions;

- guarantee of equal social and academic potential for all children [10].

However, the authors have not indicated the dependence of these factors on the preparation level of future primary school teachers to work in the inclusive education context. The problem of interaction with pupils' parents has again been left out of the researchers' attention.

Despite widespread support for inclusion at the philosophical level, there are some concerns about the fact that inclusive education policy is difficult to implement because teachers are not well prepared for the implementation of inclusive education. The researcher considers some of the obstacles to the development of successful inclusive schools and suggests ways to overcome these difficulties: reviewing teachers' roles, responsibilities and professional identity. The Inclusive Practices Project at the University of Aberdeen has been described in relation to the reform of the postgraduate education diploma [11].

Studies have shown that college teachers who were specially trained to implement inclusive education at the emotional and theoretical level have shown themselves to be genuine experts. For teacher-practitioners who have not received special knowledge and skills in the course of professional training, special training courses should be organized. Such courses should be thought out, planned and organized with an appropriate practical basis [12].

\section{Result}

As a result of the above mentioned scientific sources and empirical material analysis, we have identified the following pedagogical conditions for the effectiveness of future primary school teachers training to interact with parents in terms of inclusive education:

- stimulation of future primary school teachers' motivational-value and responsible attitude to the knowledge acquisition, skills and habits of interaction with parents in terms of inclusive education;

- the use of educational facilities for higher education institutions to acquire future primary school teachers' appropriate competence through: improvement and integration of the professional and professionally oriented academic disciplines content, application of innovative and traditional learning technologies in the context of preparation for interaction with parents in terms of inclusive education; 
- direction of educational and pedagogical practice on experience improvement of future primary school teachers' interaction with parents in terms of inclusive education (Fig. 1).

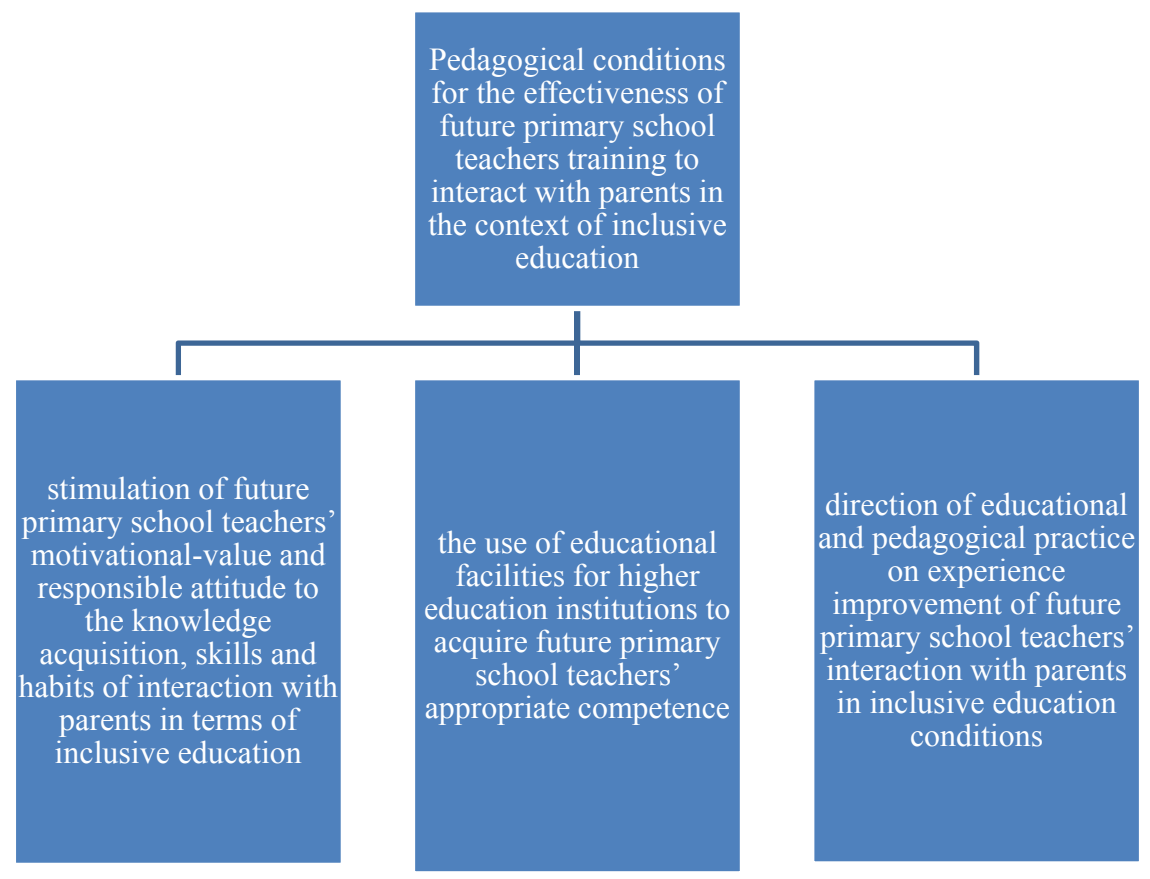

Fig. 1.Pedagogical conditions for the effectiveness of future primary school teachers training to interact with parents in terms of inclusive education

So, with regard to the second pedagogical condition, we propose a comprehensive improvement of the disciplines content with the aim of future primary school teachers training to interact with parents in the context of inclusive education. And the choice of educational disciplines of this spectrum has been realized taking into account the progress and comparison of experimental research results [8].

In the process of improving educational disciplines content with the aim of professional training of future primary school teachers to interact with parents in the context of inclusive education of academic disciplines integration, there is an appropriate use of such teaching methods: specific situations analysis; case study; roundtables, discussions, disputes, training projects, etc.

With the purpose of special teachers training to form future primary school teachers' ability to interact with parents in the conditions of inclusive education we recommend to conduct not only traditional educational and methodological or scientific-practical seminars, but also trainings, coaching, webinars, first of all, in online mode. Such forms of work nowadays become very popular because of their availability, dedication to production and innovation:

- extra-mural/distance participation;

- easy access to social networks and websites;

- the practical nature of the information: empirical material with confirmatory video stories; providing specific advice on decision making in pedagogical situations;

- the possibility of revising in case of indirect participation and in the situation of additional clarification of certain aspects;

- constant information updating taking into account the most recent trends;

- monitoring the information quality and relevance (tracking the number of visitors and analyzing their evaluation in "Likes" and direct comments, feedback, etc.).

Implementation of the third pedagogical condition (the direction of educational and pedagogical practice to improve the future primary school teachers' experience of interaction with parents in terms of inclusive education) is complicated. As experience shows, first of all, it is because of the failure of a large number of general secondary education institutions to engage 
in schoolchildren's inclusive education, despite the requirements of the current Ukrainian legislation. Consequently, in the process of passing the practice, future primary school teachers not always (not in each school) are able to acquire the necessary experience. Institutions of general secondary education are currently only at the stage of gradual requirements implementation of the current Law of Ukraine "On Education". Due to lack of educational institutions funding at the local level and the lack of didactic-methodical, psychological and pedagogical staff training, inclusive education is implemented at a generally slow pace. Therefore, responsible for the organization and follow-up of future primary school teachers' training and pedagogical practice, careful revision of the inclusive education conditions in general secondary education institutions providing relevant educational services.

At the same time, further research needs a problem of developing and implementing an experimental method of checking the effectiveness of pedagogical conditions for future primary school teachers training to interact with parents in the context of inclusive education.

\section{Conclusion}

1. So based on the scientific sources and empirical material analysis, the pedagogical conditions of future primary school teachers' preparation for interaction with parents in terms of inclusive education have been described:

- stimulation of future primary school teachers' motivational-value and responsible attitude to the knowledge acquisition, skills and habits of interaction with parents in terms of inclusive education;

- the use of educational facilities for higher education institutions to acquire future primary school teachers' appropriate competence;

- direction of educational and pedagogical practice on experience improvement of future primary school teachers' interaction with parents in terms of inclusive education.

2. However, only a concerted adherence to all conditions will be a guarantee of qualitative future primary school teachers training to interact with parents in terms of inclusive education.

\section{References}

[1] Ahmmed, M., Mullick, J. (2014). Implementing inclusive education in primary schools in Bangladesh: recommended strategies. Educational Research for Policy and Practice, 13 (2), 167-180. doi: http:// doi.org/10.1007/s10671-013-9156-2

[2] Masud, A., Sharma, U., Deppeler, J. (2012). Variables affecting teachers' attitudes towards inclusive education in Bangladesh. Journal of Research in Special Educational Needs, 12 (3), 132-140. doi: http://doi.org/10.1111/j.1471-3802.2011.01226.x

[3] Mukhopadhyay, S., Nenty, H. J., Abosi, O. (2012). Inclusive Education for Learners With Disabilities in Botswana Primary Schools. SAGE Open, 2 (2). doi: http://doi.org/10.1177/2158244012451584

[4] Deluca, M., Tramontano, C., Kett, M. (2014). Including Children with Disabilities in Primary School: The Case of Mashonaland, Zimbabwe. Leonard Cheshire Disability and Inclusive Development Centre. Available at: https://www.ucl.ac.uk/lc-ccr/centrepublications/workingpapers/WP26_IE_Zimbabwe.pdf

[5] Buhaiets, N. A. (2002). Profesiino-pedahohichna pidhotovka maibutnikh uchyteliv do roboty z simieiu uchnia. Kharkiv, 259.

[6] Buzduhan, O. A. (2013). Pidhotovka maibutnikh uchyteliv pochatkovykh klasiv do pedahohichnoi vzaiemodii z batkamy uchniv. Odesa, 267.

[7] Hutsuliak, L. I. (2018). Vzaiemodiia pedahohiv, batkiv i hromady v sotsialno-osvitnomu seredovyshchi pochatkovoi shkoly u Spoluchenykh Shtatakh Ameryky. Uman, 20.

[8] Demchenko, I. I. (2015). Pidhotovka vchytelia do roboty v inkliuzyvnii pochatkovii shkoli. Uman: FOP Zhovtyi O. O., 500.

[9] Pro osvitu (2017). Zakon Ukrainy. 05.09.2017. No. 2145-VIII. Available at: http://zakon0.rada. gov.ua/laws/show/2145-19

[10] Efthymiou, E., Kington, A. (2017). The development of inclusive learning relationships in mainstream settings: A multimodal perspective. Cogent Education, 4 (1). doi: http://doi.org/10.1080/233118 6x.2017.1304015 
[11] Rouse, M. (2008). Developing Inclusive Practice: A Role for Teachers and Teacher Education? Education in the North, 16. Available at: http://www.abdn.ac.uk/eitn/journal/46/

[12] Avramidis, E., Bayliss, P. Burden, R. (2000). A Survey into Mainstream Teachers' Attitudes Towards the Inclusion of Children with Special Educational Needs in the Ordinary School in one Local Education Authority. Educational Psychology, 20 (2), 192-211. doi: http://doi.org/10.1080/713663717

\title{
CHARACTERISTICS OF PEDAGOGICAL CONDITIONS OF RESPONSIBLE ATTITUDE TOWARDS STUDENTS' FUTURE PROFESSION FORMATION IN PEDAGOGICAL UNIVERSITIES
}

\author{
Kateryna Zhytnukhina \\ Primary Education Department \\ Pavlo Tychyna Uman State Pedagogical University \\ 2 Sadova str., Uman, Ukraine, 20300
}

\begin{abstract}
The article gives characteristics of pedagogical conditions of responsible attitude towards students' future profession formation in pedagogical universities based on the analysis of scientific sources and empirical material:

1) purposeful motivation, awareness of the need for the formation of the specified quality as the future teacher's spiritual value (motivational-value component of a responsible attitude to the future profession formation);

2) improvement of students' educational and non-auditing activities content in pedagogical universities (cognitive component);

3) organization of student activity on the implementation of responsible organizational and teaching assignments (operational and activity component).

It is substantiated that the second pedagogical condition is realized by deepening the future teachers' educational professional training disciplines content (classroom educational activity) as educational material of the given direction in order to master professional duty requirements; students' non-auditing educational activities through the circle "Pedagogical Volunteering" functioning. It is indicated that the third pedagogical condition is realized by the way of: student self-government, aimed at organizing various educational activities for the purpose of multi-role execution of responsible orders by the students, modern methods of using future teachers' self-education on a reflection basis; application of interactive forms and methods in extra-curriculum educational work; organization of managerial interaction between the practice organizers at different levels and educational institutions in order to monitor the formation of a responsible attitude towards students' future profession.However, only the harmonization of the general pedagogical conditions will be a prerequisite for the effective formation of a responsible attitude towards the students' future profession in pedagogical universities.
\end{abstract}

Keywords: pedagogical conditions, future teachers, responsible attitude towards future profession, students' education in pedagogical universities.

\section{Introduction}

Modern society is characterized by a polarity of values and inconsistency of social requirements with their observance in various spheres of Ukrainian activity: irresponsibility in professional duties performance has been massively stated, despite the fact that in the second paragraph of the updated version of the current Law of Ukraine "On Education", the purpose of education is defined as "... the education of responsible citizens who are capable of conscious social choice and directing their activities in favor of other people and society..." [1]. In the same document, the same indicators of the fifth and sixth levels of the National Qualifications Framework establish the ability of a person to "be responsible for the results of his activity and control other people in certain situations" [1]. Responsibility for rules observance and professional duties fulfillment is an actual problem of our country's Ukraine's present not only in the context of specified Law observance, but 